\title{
Alcohol Consumption and Its Adverse Effects in Poland in Years 1950-2005
}

\author{
Agnieszka Bielinska-Kwapisz ${ }^{1}$ and Zofia Mielecka-Kubien ${ }^{2}$ \\ ${ }^{1}$ College of Business, Montana State University, Bozeman, MT 59717, USA \\ ${ }^{2}$ Department of Econometrics, University of Economics, 40-226 Katowice, Poland \\ Correspondence should be addressed to Agnieszka Bielinska-Kwapisz, akwapisz@montana.edu
}

Received 20 December 2010; Accepted 12 February 2011

Academic Editor: Colin C. Williams

Copyright ( 2011 A. Bielinska-Kwapisz and Z. Mielecka-Kubien. This is an open access article distributed under the Creative Commons Attribution License, which permits unrestricted use, distribution, and reproduction in any medium, provided the original work is properly cited.

This study examines changes in alcohol consumption and its adverse effects in Poland from 1950 to 2005. First, we estimate the total alcohol demand function and test Becker and Murphy's (1988) rational addiction model. Next, we explore substitution effects between beer, wine, and spirits and report income and own- and cross-price elasticities of demand for beer, wine, and spirits. Finally, we examine some adverse effects of alcohol consumption: traffic accidents, suicide rates, and vandalism rates. In particular, the effect of lowering the blood alcohol level limit (BAC) on traffic accidents is estimated.

\section{Introduction}

The consumption of alcoholic beverages is of interest to policy makers because alcohol is one of the most heavily taxed consumer goods, and governments see alcohol beverage taxation as a valuable source of revenue. The Polish government receives more than $20 \%$ of its tax revenue from excise taxes on alcohol, cigarettes, and gasoline ("akcyza" taxes). Alcohol is an attractive target of government tax collectors because excessive alcohol consumption creates negative externalities. The external costs include direct physical, psychological, or emotional harm to others. Also, treatment costs are often borne by third parties via private or government insurance. It is estimated that the total costs associated with alcohol drinking resulting from welfare, health service, insurance, enforcement, and penal costs as well as loss of production costs accrue to a total social cost of $1-3 \%$ of GDP in the European region [1]. For the USA, the National Instituteon Drug Abuse and the National Institute on Alcohol Abuse and Alcoholism [2] report the estimated economic cost of alcoholism and alcohol abuse to amount about 3\% of GDP per year ( $\$ 148$ billions). The WHO's "The European health report" [1] states that alcohol is associated with deaths of 55,000 young people in the European region each year which accounts for one in four deaths among adolescents aged 15-29. As reported by the WHO [3], road accidents are the fourth leading cause of death worldwide for people aged 15-59. Albalate [4] reports that more than 41,000 people died and 1.9 million were injured on European roads in 2005, and more than 43,000 road users died and 2.5 million were injured in that same year in the USA Clearly, there is a constant need for governments to continue efforts to reduce these numbers worldwide. However, the success of government policies to reduce excessive alcohol consumption and to collect the expected revenue from alcohol taxation depends crucially on own- and cross-price elasticities of demand for various types of alcohol beverages. It is believed that alcohol beverages are inelastically demanded. A growing number of studies have explored alcohol consumption and relative effectiveness of various antidrunk driving policies in the U.S., but the literature comparing alcohol consumption, crash rates, and anti-drunk driving policies between different countries is relatively sparse. We hope to fill this gap by studying alcohol consumption and its adverse effects in Poland. To our knowledge, this is so far the most comprehensive study on this subject for Poland. The only other study, by Florkowski and McNamara [5], estimates the single-equation demand models for alcohol and tobacco for 1959-1985. They find vodka and tobacco consumption to be price inelastic 
and stress an importance of alcohol revenue to the Polish government as a way to reduce a budget deficit.

We use a newly constructed data set that covers years from 1950 to 2005. However, since statistical data (that are widely available in the U.S.) are not so easily obtainable in Poland (especially for the earlier years), some of our variables may contain a substantial measurement error that was unavoidable. Poland is a leading country in the Central and Eastern Europe that has moved from a one-party political system and a centrally planned economy to a parliamentary democracy and a market economy. The first democratic parliamentary election took place in June 1989. Poland became a member of the European Union in May 2004. This transformation brought many changes in Polish laws, road safety, and attitudes toward drinking.

Since the price of alcohol can be manipulated through excise tax policies (Young and Bielińska-Kwapisz [6] show how alcohol taxes are passed onto prices), our findings are very relevant for policy makers whose objective is to reduce adverse effects of alcohol consumption and to gather tax revenue. Presently in Poland, the maximum excise alcohol tax is 6.3 thousands zloty for 1 hectoliter of ethanol (100\%). This is going to decrease to 4.55 thousands zloty at the beginning of 2008 in order to comply with the European Union legislation. In the case of wine, the decrease will be from 300 zloty for 1 hectoliter of wine to 136 zloty, and the rate for beer will not change and stay at 6.86 zloty for 1 hectoliter (retrieved from http://www.money.pl/podatki/wiadomosci/artykul/wzrosnie _akcyza_na_papierosy_i_alkohol,97,0,238945.html on July 2, 2007). The one of the unwanted effects of this legislation may be increase in alcohol consumption and its adverse effects. Our analysis will help to predict how strong these effects might be.

In the next section, we present trends and patterns of alcohol consumption in Poland and compare them to Europe and the U.S. In Section 3, we estimate the total alcohol demand equation using the rational addiction model. In Section 4, using the Almost Ideal Demand System, we estimate the substitution effects between beer, wine, and spirits. Sections 5 and 6 deal with the adverse effects of alcohol consumption: traffic accidents, suicide rates, and vandal behaviors. We conclude and present policy implications in Section 7.

\section{Trends and Patterns of Alcohol Consumption, Liver Cirrhosis, and Accidents in Poland in Years 1950-2005}

Figure 1 presents trends in the apparent total consumption of ethanol in liters per capita (age 15 and over) in Poland and the U.S. from 1950 to 2005. In line with previous studies (see, e.g., Nelson and Moran [7], Nelson [8], and Young and Bielinska-Kwapisz $[6,9,10])$ the total ethanol consumption was constructed by assuming that beer has an alcohol content of 4 percent, wine 12.5 percent, and spirits 40 percent.

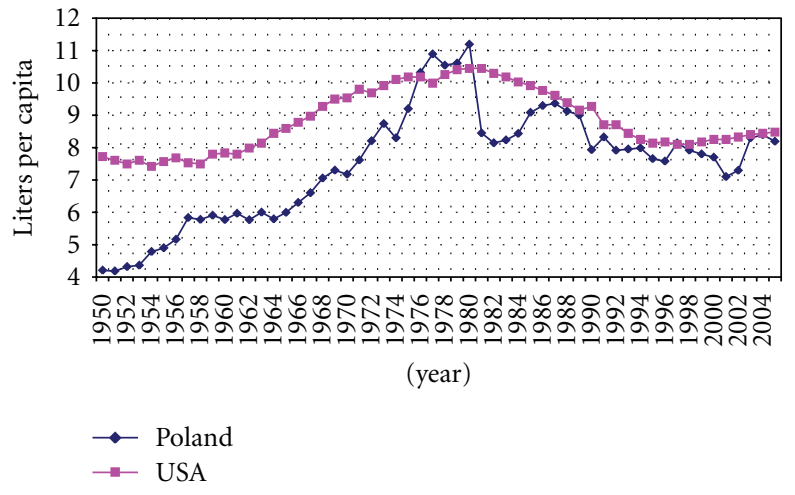

Figure 1: Apparent per capita total ethanol consumption.

During the years 1950-2005, Poland underwent huge changes in alcohol consumption. Starting with a relatively low (recorded) consumption level of 4.2 liters of pure alcohol per capita in 1950, the level increased 2.5 times by 1980 when the apparent total consumption peaked at 11.2 liters (2.96 gallons) of pure alcohol per capita. During the time when Poland was under a socialist government (before 1980), the government often used alcohol to sooth economic difficulties. In 1970, the tax revenue from the alcohol industry constituted 9\% of the total Polish budget [11]. During this time, the government censored news about alcohol problems as well as data on alcohol revenue since there was no place for such problems in the propaganda of success [11]. In the second part of the 70s, the opposition accused the government of purposely pushing alcohol to the society. This may have been one of the reasons that caused a significant change in the government's alcohol policy in 1978 when alcohol prices were significantly increased, alcohol availability become limited by restricting hours and days of sale, and censorship was considerably weakened. As a result, after 1980, consumption started to decrease significantly. At the beginning of the 80 s, the Solidarity movement began, and strikes against the socialist government broke out. During strikes, workers imposed, and strictly enforced, a prohibition on themselves in order to not to be seen as uncontrolled rebels [12]. As part of the maneuvering, the government took over the antialcohol movement, and the complex Alcohol Act of Parliament was passed as a part of the agreement between the government and Solidarity in 1982 [13]. However, soon after, the act was amended twice liberating its provisions and, once again, alcohol problems vanished from sight and ceased to be a public issue, alcohol wholesale was privatized, selling restrictions were lifted, and the act from 1982 began to loose its effectiveness. As a consequence, alcohol consumption began to increase and level off at about 8.2 liters per capita in 2005 .

In the U.S., the apparent consumption of ethanol per capita (age 14 and over) peaked in 1980 and 1981 at 2.76 gallons after years of steady growth and declined steadily from the early 1980s to mid- 1990s before leveling off at about 2.2 gallons of pure ethanol per capita. In 2003, compared to other European countries in Poland placed 22 in per capita alcohol consumption among all EU countries 


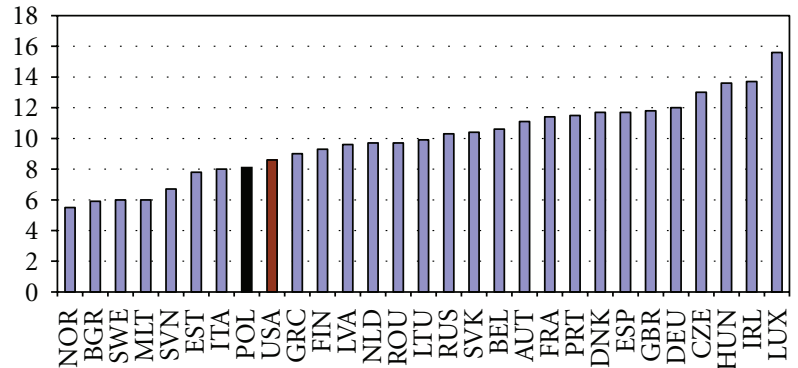

Figure 2: Per capita alcohol consumption in liters, 2003, all EU, US, Norway, and RF.

and Russian Federation, Norway, and the U.S. (see Figure 2 and Table 1). Based on the 2003 data, the apparent per capita alcohol consumption in Poland is about the same as in the United States and lower than in most of Europe. The highest per capita consumption was observed in Luxembourg being almost twice as high as Poland and the U.S.

Also, alcohol consumption underwent huge changes over this time period in Poland, especially in recent years. Figure 3 shows per capita (age 15 and older) consumption of beer, wine, and spirits. Spirits consumption was the highest during the years 1950-1999. After 1994, spirits consumption began to decline significantly, while beer consumption increased and was higher than spirits consumption in 2000. In recent years (2003-2005), spirits consumption increased again, beer consumption continued to increase, and wine consumption declined slightly.

In 2005, per capita (age 15 and older) consumption of beer was 3.9, spirits 3.0, and wine 1.3 liters. The share of spirits in overall alcohol consumption declined from $77 \%$ in 1950 to $37 \%$ in 2005 , while the share of beer increased substantially from $13 \%$ in 1950 to $47 \%$ in 2005 , and the share of wine increased from $4 \%$ in 1950 to $16 \%$ in 2005 (see Figure 4).

It is important to note that the above data reflect recorded alcohol consumption from official records. However, in Poland, alcohol is also available from home production, illegal imports, and cross-border shopping, which lay outside of the recorded statistics. It is hard to accurately estimate the level of unrecorded alcohol consumption; however, the World Health Organization (WHO) estimated the volume of unrecorded consumption in Poland to be 3.0 liters of pure alcohol per capita for population age of 15 and older for the years after 1995 [14]. According to the WHO, the biggest increase in unrecorded consumption happened in 1990 and 1991 when it was estimated at 4 liters, which corresponded to the two thirds of the recorded consumption [14]. Popova et al. [15] report that main beverage of unrecorded consumption in Poland is bimber, samogon, ksiezycowka (homemade liquor: $40-60 \%$ of alcohol), sliwowoica, and lacka sliwowica (moonshine made from distilling plumps: $40-60 \%$ of alcohol).

Figure 5 shows how deaths from liver cirrhosis per 100,000 population age of 20 and older closely follow the alcohol consumption pattern in Poland. Over the years from

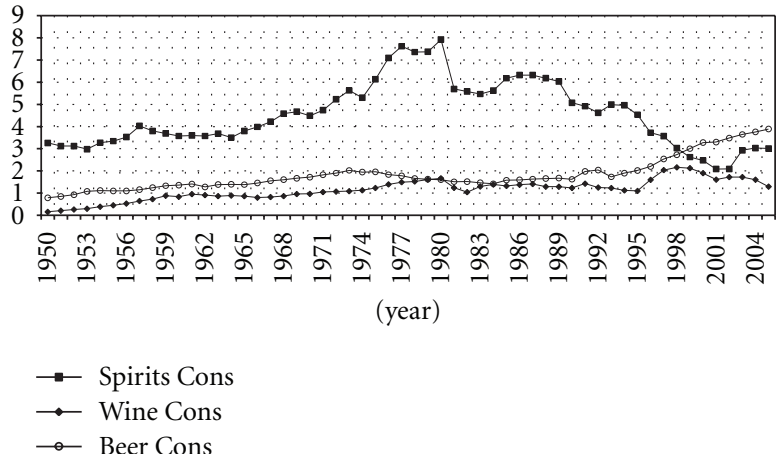

Figure 3: Structure of alcohol consumption, Poland, liters per capita, 1950-2005.

1959 to 2005, deaths due to liver cirrhosis steadily increased from 4.98 to 15.74 . It peaked at 17.94 in 1980 and reached its second peak in 1995 when the rate was at the highest level of 18.35 deaths per 100,000 population age 20 and older.

\section{Demand for Alcohol in Poland}

This section presents the results of estimations of the total alcohol demand equation and deaths due to liver cirrhosis equation in Poland. Section 3.1 presents data and explains methods used. Section 3.2 presents results.

3.1. Methods. The descriptive statistics for all our variables are presented in Appendix A. Quantities of beer, wine, and spirits are multiplied by their average alcohol content (4.5\%, $12.5 \%$, and 40\% resp.,) and expressed as liters of pure ethanol per capita (age 15 and older). Data on alcohol consumption, prices of specific alcohol beverages, and income were obtained from the Statistical Yearbooks of the Republic of Poland, 1956-2006 [16]. The real price of total alcohol is defined as the price index of alcoholic beverages divided by the price index of all consumer goods and services $(1990=100)$. Data on liver cirrhosis are from archives of the Central Statistical Office (1959-1970) and the Demographic Yearbooks of Poland [17]. The population data are taken from the Demographic Yearbooks of Poland.

A consumption good is called addictive when an increase in past consumption causes the present consumption to rise. This is also a sufficient condition for consumer's preferences to be called myopic. Therefore, current alcohol consumption for myopic consumers depends on current price, past consumption, wealth, and other current events. However, rational consumers will additionally consider future consequences of current consumption. We use the rational addiction model of alcohol consumption developed by Becker and Murphy [18] who showed how an individual who already had an established addiction with a set of stable, forward looking preferences will remain an addict. For the U.S., a strong support for the alcohol consumption rational addiction model was found by, for example, Waters and Sloan [19] and Grossman et al. [20]. 
TABLe 1: Per capita alcohol consumption, all EU, US, Norway, and RF, selected years.

\begin{tabular}{|c|c|c|c|c|c|c|}
\hline & & 2003 & 1990 & 1980 & 1970 & 1961 \\
\hline Austria & AUT & 11.1 & 12.6 & 13.8 & 13.9 & 11 \\
\hline Belgium & BEL & 10.6 & 12.1 & 13.5 & 11.6 & 9.9 \\
\hline Bulgaria & BGR & 5.9 & 11.7 & 11.2 & 8.7 & \\
\hline Czech Rep & CZE & 13 & 11.2 & 12.5 & 10.7 & 10.4 \\
\hline Denmark & DNK & 11.7 & 11.7 & 11.5 & 8.9 & 6.5 \\
\hline Estonia & EST & 7.8 & & & & \\
\hline Finland & FIN & 9.3 & 9.5 & 7.9 & 5.8 & 2.9 \\
\hline France & FRA & 11.4 & 15.8 & 19.2 & 21.5 & 26 \\
\hline Germany & DEU & 12 & 12.6 & 14 & 13.3 & 11 \\
\hline Greece & GRC & 9 & 10.7 & 13.2 & 7.1 & \\
\hline Hungary & HUN & 13.6 & 13.9 & 15 & 11.5 & 9 \\
\hline Ireland & IRL & 13.7 & 10.4 & 10.5 & 8.6 & \\
\hline Italy & ITA & 8 & 11 & 16.7 & 18.2 & 19.2 \\
\hline Latvia & LVA & 9.6 & 6.9 & 13 & & \\
\hline Lithuania & LTU & 9.9 & 6.5 & & & \\
\hline Luxembourg & LUX & 15.6 & 14.7 & 13.7 & 12.9 & \\
\hline Malta & MLT & 6 & 6.9 & & & \\
\hline Netherlands & NLD & 9.7 & 9.9 & 11.5 & 7.8 & 4 \\
\hline Norway & NOR & 5.5 & 5.1 & 5.9 & 4.8 & 3.7 \\
\hline Poland & POL & 8.1 & 8.3 & 11.5 & 7.6 & 6.3 \\
\hline Portugal & PRT & 11.5 & 16.1 & 14.9 & 14.5 & \\
\hline Romania & ROU & 9.7 & 10.9 & 10.9 & 8.5 & 5.7 \\
\hline Russian Federation & RUS & 10.3 & 7.1 & 7.9 & 8.9 & \\
\hline Slovakia & SVK & 10.4 & 12.4 & 13.7 & 11.5 & 9.3 \\
\hline Slovenia & SVN & 6.7 & 13.8 & & & \\
\hline Spain & ESP & 11.7 & 13.6 & 18.5 & 16.1 & \\
\hline Sweden & SWE & 6 & 6.7 & 7.1 & 7.3 & 6 \\
\hline United Kingdom & GBR & 11.8 & 9.5 & 9.6 & 6.7 & 7.1 \\
\hline United States & USA & 8.6 & 9.3 & 10.7 & 9.3 & 7.4 \\
\hline
\end{tabular}

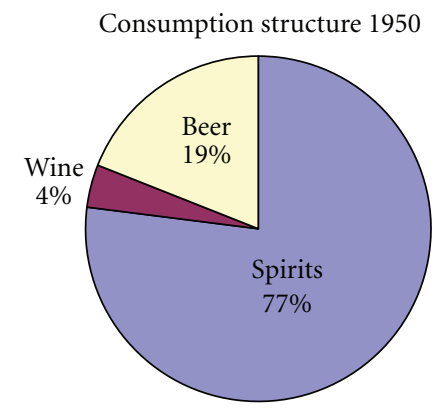

(a)
Consumption structure 2005

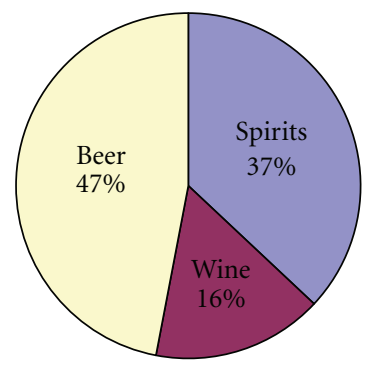

(b)

Figure 4: Structure of alcohol consumption in Poland. Years 1950 and 2005.

Since our time series data exhibit strong trends and are not stationary, we use our series in the first differences. The model specification is:

$$
\begin{aligned}
& \Delta \text { Alcohol Cons }_{t} \\
& \begin{aligned}
= & \beta_{0}+\beta_{1} \Delta \text { Alcohol Cons }_{t-1}+\beta_{2} \Delta \text { Alcohol Cons }_{t+1} \\
& +\beta_{3} \Delta \text { Price }_{t}+\beta_{4} \Delta \text { Income }_{t}+\beta_{5} D_{t}+\varepsilon_{t} .
\end{aligned}
\end{aligned}
$$

The change (from time $(t-1)$ to $t$ ) in current alcohol consumption $\left(\Delta\right.$ Alcohol Cons $\left.{ }_{t}\right)$ is explained by changes in past (at $t-1)$ and future (at $t+1)$ consumption, change in current price level $\left(\Delta\right.$ Price $\left._{t}\right)$, income $\left(\Delta\right.$ Income $\left._{t}\right)$, and a dummy variable $D_{t}$ that takes the value 1 on and after the year 1989 and 0 for the earlier years. The dummy $D_{t}$ represents the time after the first democratic parliamentary election in Poland. (Also, a vector of the following socioeconomic variables: the share of population over age 65 , the share of population aged 


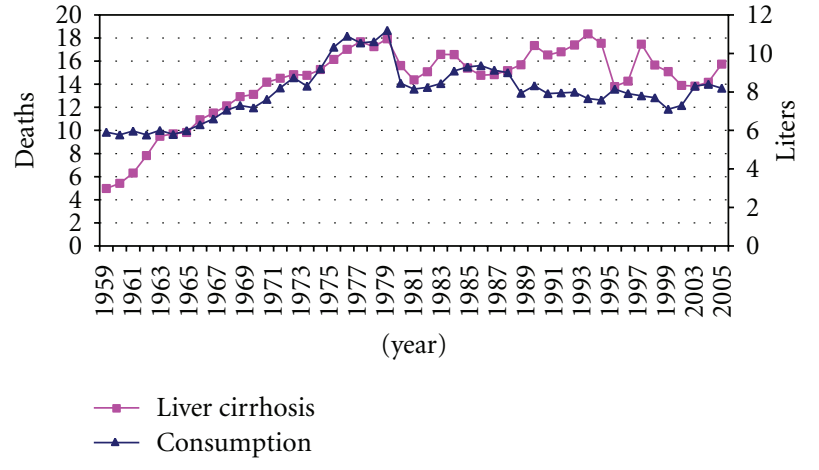

FIGURE 5: Deaths from liver cirrhosis.

TABle 2: Estimates of alcohol consumption in Poland $(n=49)$.

\begin{tabular}{lccc}
\hline & Coeff. & Std.Err. & $P$ value \\
\hline Constant $_{\Delta \text { Alcohol Cons }_{t-1}}$ & 0.10 & 0.07 & .17 \\
$\Delta$ Alcohol Cons $_{t+1}$ & $-0.36^{*}$ & 0.11 & .00 \\
$\Delta$ Price $_{t}$ & -0.09 & 0.10 & .37 \\
$\Delta$ Income $_{t}$ & $-4.99^{*}$ & 0.73 & .00 \\
Free market & $0.01^{*}$ & 0.00 & .00 \\
$R$-squared & $-0.59^{*}$ & 0.13 & .00 \\
\hline
\end{tabular}

${ }^{*}$ Significant at $0.01 \%$ level.

$15-20$, and the share of population living in urban areas was added, but the effects were insignificant.)

3.2. Results. We report the regressions results of (1) in Table 2.

Our results imply that alcohol demand is consistent with the myopic model of addiction but not with the rational addiction model. Current consumption is positively affected by lagged consumption but not by future consumption. As expected, demand is negatively affected by its own price and positively affected by income (for the U.S. price elasticities see, e.g., Leung and Phelps [21] or Young and BielińskaKwapisz [9]). Moreover, the dummy variable "free market" has a highly significant and negative coefficient. This variable accounts for the change from the communism to a freemarket economy and captures the effect of the various policies Polish government passed to reduce drinking and its negative consequences in the 1980s and later (such as the mandatory seat belt law, the mandatory back seat belt law, and a lower BAC level) as well as the efforts to increase public awareness of negative consequences of drinking.

Most of adverse effects of alcohol consumption are due to heavy, binge, and long-term drinking. However, data on this type of alcohol consumption are hard to obtain since aggregate data show all types of consumption, and survey data tend to underestimate heavy and long-term drinking. Following Cook [22], Cook and Tauchen [23], and Brown and Jewell [24], we use cirrhosis mortality as an indicator of heavy drinking keeping in mind that cirrhosis results
Table 3: Estimates of deaths due to liver cirrhosis in Poland ( $n=$ 45).

\begin{tabular}{lccc}
\hline & Coeff. & Std.Err. & $P$ value \\
\hline Constant & 0.337 & 0.221 & .135 \\
$\Delta$ PRICE & -3.017 & 2.154 & .169 \\
$\Delta$ INCOME & 0.003 & 0.003 & .367 \\
Free market & -0.564 & 0.379 & .145 \\
$R$-squared & 0.072 & & \\
\hline
\end{tabular}

from excessive drinking over a longer period of time (1020 years), and the cirrhosis mortality rates may not reflect current heavy drinking. According to Cook and Moore [25], "Cirrhosis is characterized by a progressive replacement of healthy liver tissue with scarring, leading to liver failure and death. While it has a variety of causes, alcohol accounts for a majority of cases within population groups where drinking is widespread; indeed, the cirrhosis-mortality rate has long been used as an indicator of the prevalence of alcoholism in a population [26]. The likelihood of cirrhosis is closely related to lifetime consumption; according to one review, an individual weighing 150 pounds who drank 21 ounces of 86 proof whiskey per day for 20 years would have a 50 percent chance of suffering from cirrhosis [27]."

Our estimates of the death rates due to liver cirrhosis are presented in Table 3. As before, we have estimated our model in differences to correct for autocorrelation. However, the whole regression is not significant. As expected, longtime, heavy, and binge drinkers do not react to price changes the same as total population. The price coefficient has a correct sign but is not statistically significant at any level of significance. This result suggests that the population at risk for alcohol-related cirrhosis-long-term drinkers-is not price sensitive. Other variables are also not statistically significant.

These results suggest that increasing the price of alcohol by rising taxes may have limited result on reducing problems associated with long-term, heavy, and binge drinking.

\section{Substitution Effects between Drinks (Almost Ideal Demand System)}

In this chapter, we investigate substitution possibilities for consumption of beer, wine, and spirits in Poland. We present data and methodology in Section 4.1 and results in Section 4.2.

4.1. Methods. Until relatively recently, most researchers estimated alcohol demand systems by using single-equation methods (see, e.g., Johnson and Oksanen [28, 29], Lau [30], and Coate and Grossman [31]). The approach we use in modeling and estimating the demand for alcohol beverages assumes a two-stage budgeting process on the part of the consumers. Consumers allocate expenditure first to the total alcohol consumption and then to the alcohol consumption within each group: beer, wine, or spirits. The second-stage consumption decision is modeled by a system of demand 
equations known as the Almost Ideal Demand System (AIDS) of Deaton and Muellbauer [32]. Authors who estimated alcohol demand systems include Clements and Johnson [33] and Clements and Selvanathan [34, 35] for Australia, the U.K., and the U.S., Duffy [36] for the U.K., Heien and Pompelli [37] and Nelson and Moran [7] for the U.S., and Andrikopoulos et al. [38] for the province of Ontario.

Many empirical systems of demand have been estimated using the translog or Rotterdam models. The Almost Ideal Demand System (AIDS) model is of comparable generality but has considerable advantages over both translog and Rotterdam models; the AIDS model gives an arbitrary firstorder approximation to any demand system; it satisfies the axioms of choice exactly; it aggregates perfectly over consumers without invoking parallel linear Engel curves; it has a functional form which is consistent with known household-budget data; it is simple to estimate.

The AIDS model is derived from a specific class of preferences, known as the PIGLOG class, which are represented by a cost function $C(u, p)$ that is given on the utility $u$ and the price vector $p$ by

$$
\operatorname{Ln} C\{u, p\}=(1-u) \ln \{A(p)\}+u \ln \{B(p)\} .
$$

Here, $u$ lies between zero and one, and $A(p)$ and $B(p)$ are linear, homogeneous, and concave functions defined as

$$
\begin{aligned}
& \ln A(p)=\alpha_{0}+\sum_{k} \alpha_{k} \ln p_{k}+\frac{1}{2} \sum_{k} \sum_{j} \pi_{k j} \ln p_{k} \ln p_{j} \\
& \ln B(p)=\ln A(p)+\beta_{0} \prod_{k} p_{k}^{\beta_{k}} .
\end{aligned}
$$

By Shephard's lemma, we get the demand functions in the following budget share form $w_{i}=\alpha_{i}+\beta_{i} \ln (M / P)+$ $\sum_{j=1}^{n} \pi_{i j} \ln p_{j}$ where $w_{i}=p_{i} q_{i} / M$ is the budget share of the $i$ th beverage, $M=p_{b} q_{b}+p_{s} q_{s}+p_{w} q_{w}$ is the total expenditure on alcohol, and $P$ is the price index defined by

$$
\ln P=\sum_{i=1}^{n} \alpha_{i} \ln p_{i}+\frac{1}{2} \sum_{i=1}^{n} \sum_{j=1}^{n} \gamma_{i j} \ln p_{i} \ln p_{j} .
$$

Figure 6 shows the conditional budget shares $\left(w_{i}\right)$ over the years in Poland. The share of beer in total alcohol spending has increased by about 12 percentage points over the sample period to reach $14.3 \%$ in 2005 . Most of this increase was offset by the decrease in the share of spirits from $89 \%$ in 1953 to $70 \%$ in 2005 . The wine share was $15 \%$ in 2005 .

The adding up, homogeneity, and symmetry restrictions on the parameters are as follows: $\sum \alpha_{i}=1, \sum \beta_{i}=$ $0, \sum_{i} \pi_{i j}=0, \sum_{j} \pi_{i j}=0$, and $\pi_{i j}=\pi_{j i}$. The price index can be approximated by the Stone index $\ln P \cong$ $\sum_{i} w_{i} \ln p_{i}$ to eliminate nonlinearities in the parameters. In order to avoid singularity of the residual covariance matrix, we impose adding up restriction by dropping one of the equations, (the one for wine). Therefore, we are left with two equations (for beer and spirits) that are going to be estimated simultaneously with homogeneity and symmetry restrictions imposed. The parameters for the third equation are calculated from the restrictions in the following way:

$$
\begin{gathered}
\alpha_{w}=1-\left(\alpha_{b}+\alpha_{l}\right), \\
\beta_{w}=-\left(\beta_{b}+\beta_{l}\right), \\
\pi_{w b}=\pi_{b w}, \\
\pi_{w l}=\pi_{l w}, \\
\pi_{w w}=-\left(\pi_{b w}+\pi_{l w}\right) .
\end{gathered}
$$

We assume that the consumer's utility function is weakly separable with respect to alcohol and other goods and services. The assumption of weak separability ensures that this is a correct model and that the demand equations for particular alcohol types depend on the prices of nonalcohol goods and services only through their effects on the total alcohol expenditure.

The first stage of estimation uses the composite demand equation for total alcohol as given by [37]

$$
\frac{M}{Y}=\delta_{0}+\delta_{1} \ln P+\delta_{2} \ln Y+\delta_{3} \ln Z,
$$

where $M$ is the alcohol expenditure, $Y$ is the total income, $\ln P$ is the Stone index, $\ln Z$ is the price index for all nonbeverage items, and $\delta_{i}$ are parameters to be estimated. Under the assumption that all consumers face the same prices for non-beverage items, the effect of $Z$ will be absorbed in the intercept. In Appendix B, we show how conditional elasticities (since they depend on the total alcohol consumption) and unconditional (total) elasticities are calculated.

We estimated the system of demand equations for beer, spirits, and wine in the following form:

$$
w_{i}=\rho_{i 0}+\beta_{i}\left(\ln M-\sum_{j=1}^{3} w_{j} \ln p_{j}\right)+\sum_{j=1}^{3} \pi_{i j} \ln p_{j},
$$

where $w_{i}$ is the budget share for the $i$ th beverage, $M$ is the total alcohol expenditure, $p_{j}$ are the prices for beer, spirits, and wine, and $\rho, \beta$, and $\pi$ are parameters to be estimated.

4.2. Results. Table 4 shows the estimated price and expenditure coefficients and elasticities evaluated at the sample means. All coefficients were significant at the $1 \%$ level except the beer-wine coefficient. We call these elasticities conditional since the total alcohol consumption is held constant.

The estimated income elasticities of demand indicate that demand for beer is income inelastic (i.e., beer is a necessity) while demand for spirits is elastic (i.e., spirits are luxury goods). The wine elasticity is almost one (0.9), pointing that wine is somewhat income elastic, too. The uncompensated own-price elasticities of demand indicate that all demands for alcoholic beverages are price inelastic (absolute value of elasticities less than one). For example, a $1 \%$ increase in the price of spirits leads to a decrease in demand for spirits by about $0.9 \%$ (keeping the total alcohol expenditure constant). The price elasticity for beer is positive but very close to 
Table 4: Price and expenditure coefficients and elasticities.

\begin{tabular}{|c|c|c|c|c|c|c|c|c|c|c|c|}
\hline \multirow{2}{*}{ Variable } & \multicolumn{4}{|c|}{ Coefficients } & \multicolumn{3}{|c|}{ Uncompensated Price elasticity } & \multicolumn{3}{|c|}{ Compensated Price elasticity } & \multirow{2}{*}{$\begin{array}{l}\text { Income } \\
\text { Elasticities }\end{array}$} \\
\hline & $\begin{array}{l}\text { Beer } \\
\text { price }\end{array}$ & $\begin{array}{l}\text { Spirits } \\
\text { price }\end{array}$ & $\begin{array}{l}\text { Wine } \\
\text { price }\end{array}$ & $\log (M / P)$ & $\begin{array}{l}\text { Beer } \\
\text { price }\end{array}$ & $\begin{array}{l}\text { Spirits } \\
\text { price }\end{array}$ & $\begin{array}{l}\text { Wine } \\
\text { price }\end{array}$ & $\begin{array}{l}\text { Beer } \\
\text { price }\end{array}$ & $\begin{array}{l}\text { Spirits } \\
\text { price }\end{array}$ & $\begin{array}{l}\text { Wine } \\
\text { price }\end{array}$ & \\
\hline Beer Share & 0.04 & -0.039 & -0.002 & -0.019 & 0.03 & -0.588 & -0.039 & 0.051 & -0.146 & 0.032 & 0.0534 \\
\hline Spirits Share & -0.039 & 0.099 & -0.06 & 0.032 & -0.044 & -0.912 & -0.078 & -0.003 & -0.053 & 0.06 & 1.038 \\
\hline Wine Share & -0.002 & -0.06 & 0.062 & -0.013 & -0.007 & -0.371 & -0.547 & 0.029 & 0.373 & -0.428 & 0.9 \\
\hline
\end{tabular}

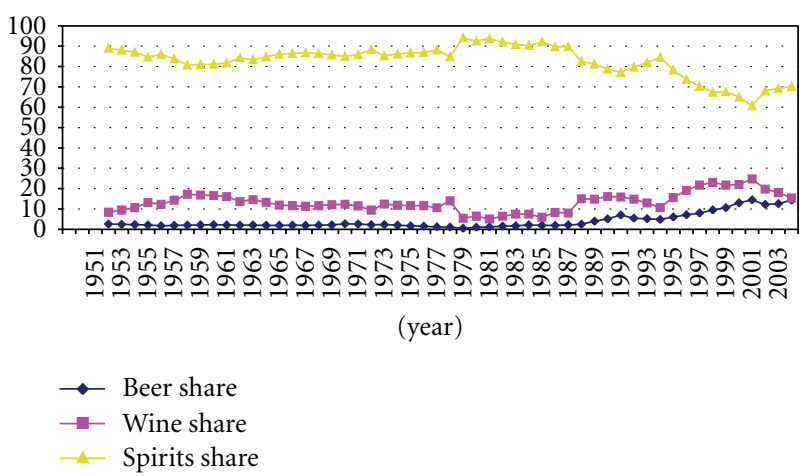

Figure 6: Conditional budget shares.

zero indicating almost no change in demand for beer as a result of an increase in its price. Summarizing, beer is not only income inelastic but also price inelastic making it an attractive target of a government tax. The compensated ownprice elasticities reveal a similar picture: all beverages have a significantly inelastic compensated demand. Now, turning to the relationships between the three types of drinks, the cross-priced compensated price elasticities indicate that beer and spirits are complements (elasticities are negative). This means that an increase in the price of spirits will not only result in the decrease in spirits consumption but also in beer consumption. Additionally, spirits are substitute for wine (elasticities are positive), but wine and beer are not significantly related (the coefficient was not significantly different from zero).

The conditional demand equations for beer, wine, and spirits assume that the total alcohol consumption is constant and is determined in the first stage of the consumers' decision process. Therefore, the conditional demand elasticities presented in Table 4 show how a price hike for a given beverage affects consumption of beer, wine, and spirits with the total alcohol consumption held constant. However, an increase in the price of a particular beverage has two possible effects on consumption. First, the direct effect, via the conditional demand functions, is the reallocation of the total alcohol expenditure between specific drinks. Second, the indirect effect, via the composite demand function, is the change in the total alcohol consumption. To obtain estimates of the total impact of all income and price changes, we substituted the composite demand equation into the conditional demand equations and calculated the unconditional elasticities.

We estimate the unconditional price and income elasticities using the (6) and report them in Table 5.

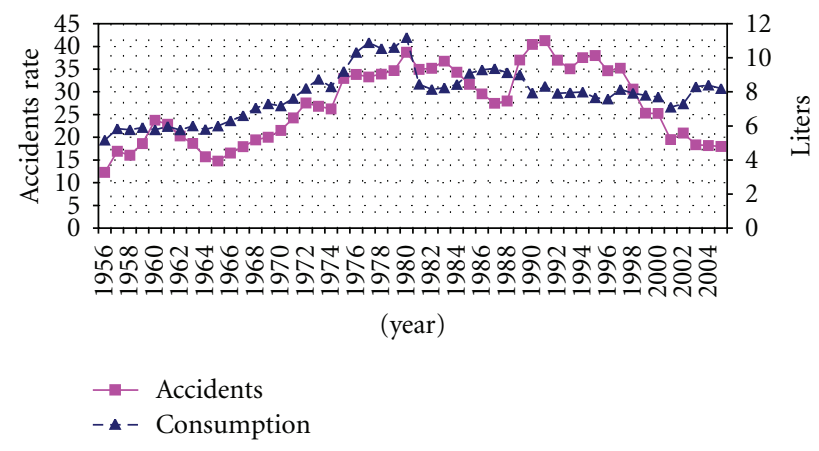

Figure 7: Motor vehicle traffic accidents rate and alcohol consumption.

The income elasticities of demand show that beer, spirits, and wine are normal goods (as all the elasticities are positive) and are income inelastic (since all the elasticities are less than one). However, spirits and wine elasticities are close to one. Similarly to the results from the conditional equations, the uncompensated own-price elasticities of demand indicate that the demands for beer, spirits, and wine are price inelastic and the compensated cross-price elasticities indicate that the pairs: spirits and beer are complements, spirits and wine are substitutes, and beer and wine are not significantly related.

\section{Estimation of Traffic Accidents}

Road traffic accidents are one of the most important negative consequences of excessive drinking. From the late 1970s, U.S. governments at the federal, state, and local levels (together with private organizations such as Mothers Against Drunk Driving) have tried to reduce drunk driving fatalities by passing new or stricter laws, stepping up enforcement, and carrying on educational campaigns. These campaigns appear to have had some success, as the U.S. alcohol-related fatalities have declined both in absolute terms and as a proportion of total fatalities (see, e.g., http://www-fars.nhtsa.dot.gov). However, alcohol remains a key factor in the enormous toll of death on the highways. In 2006, the U.S. Department of Transportation reported 17,602 alcohol-related traffic fatalities, which is about $41 \%$ percent of the total traffic fatalities (2006 Traffic Safety Fact Sheets available (accessed on July 2007) at http://www.nhtsa.gov/portal/site/nhtsa/menuitem. 6a6eaf83cf719ad24ec86e10dba046a0/). Traffic fatalities are a leading cause of premature death, particularly among people under thirty-five years of age. In 2003, the European Commission estimated that at least 10,000 road users died every year in alcohol-related accidents in Europe. Clearly, 
TABLE 5: Total (unconditional) price and income elasticities.

\begin{tabular}{lccccccc}
\hline \multirow{2}{*}{ Variable } & \multicolumn{2}{c}{ Uncompensated price elasticity } & \multicolumn{2}{c}{ Compensated price elasticity } & \multirow{2}{*}{ Expenditure elasticities } \\
& Beer price & Spirits price & Wine price & Beer price & Spirits price & Wine price & 0.057 \\
Beer Share & 0.034 & -0.509 & 0.037 & 0.054 & -0.489 & 0.057 & 0.762 \\
Spirits Share & -0.041 & -0.758 & -0.053 & 0.775 & 0.057 & 0.762 & 0.985 \\
Wine Share & -0.001 & -0.238 & -0.5 & 0.112 & -0.125 & -0.386 & 0.854 \\
\hline
\end{tabular}

the problem of drunk driving is a global problem, and governments around the world have tried to discourage drunk driving with specific regulations. In the U.S., a number of studies have estimated the relationship between alcohol taxes and/or prices on the one hand, and motor vehicle fatalities on the other hand (examples include Chaloupka et al. [39], Sloan et al. [40], Ruhm [41, 42], Benson et al. [43], Dee [44, 45], Mast et al. [46], Young and Likens [47], and Young and Bielińska-Kwapisz [10]).

In Poland, alcohol is involved in about 11 percent of all traffic fatalities. Therefore, alcohol policies-particularly those focused on drinking and driving-have the potential to significantly reduce road fatalities due to alcohol consumption. Figure 7 shows motor vehicle traffic accidents per 100,000 population (age 15 and older) compared to alcohol consumption (liters) in Poland for years 1956 to 2005.

Data on traffic fatalities that involve alcohol going back to the 50s are not available for Poland. Therefore, we use the total motor vehicle traffic accidents as a proxy for drunk driving since accidents that involve alcohol are a big portion of the total accidents. Data on traffic fatalities and on the numbers of vehicles were obtained from the Statistical Yearbooks of the Republic of Poland 1980-2006 [16] and from the Police Headquarters in Warsaw (Komenda Glowna Milicji Obywatelskiej) for 1956-1979.

In 1956, there were 12.29 motor vehicle traffic accidents per 100,000 population age of 15 and older. The highest rate of 41.29 accidents was in 1991 and, since than, the rate declined by about one-third to reach 17.98 in 2005 .

One common policy in Europe and in the U.S. has been to set the Blood Alcohol Content (BAC) limits. Currently, the BAC level in Poland is $0.02 \%$ (lowered from $0.05 \%$ in 1982 ) that is significantly lower than the one in the U.S. $(0.08 \%)$. The European Commission stresses the importance of the lower BAC levels and recommends BAC limit for the European Union to be set at $0.05 \%$. There is a significant amount of literature trying to establish the influence of the BAC level on road fatalities, but the evidence it produced is nonconclusive (see, e.g., Eisenberg [48], Dee [49], and, recently, Albalate [4]). As presented in Table 6, the alcohol level at which a person is considered to be legally impaired varies from anything above zero to $0.08 \%$ in different countries.

Below, we present the estimation of the regression model that expresses the traffic accidents rate as a function of alcohol consumption, real per capita income, the dummy variable for the .02 BAC level, and a number of vehicles per capita in Poland. To account for the autocorrelation, we estimated the model in the first differences. We used semilogarithm model of differenced data for the traffic accidents in the following form:

$$
\begin{aligned}
\Delta \log (\mathrm{Acc})= & \beta_{1}+\beta_{2} * \Delta(\text { Cons })+\beta_{3} * \Delta(\text { Income }) \\
& +\beta_{4} * \Delta(\text { Vehicles })+\beta_{5} * \mathrm{BAC}_{20}+\varepsilon
\end{aligned}
$$

where Acc is the number of accidents per 10,000 population 15 years and older, Cons is the per capita ( 15 and older) total alcohol consumption, Income is the real annual per capita income, Vehicles is the per capita number of vehicles, $\mathrm{BAC}_{20}$ is a dummy variable that takes a value of 1 after the year 1982 when the BAC level was lowered from .05 to .02 , and zero otherwise. Symbol $\Delta$ stands for a change from year $i$ to $i-1$, $\beta$-s are the coefficients to be estimated, and $\varepsilon$ is a random error term. We present our regression results in Table 7.

The estimated magnitudes suggest a significant effect of alcohol consumption on the total traffic accidents. A ten-percent increase in alcohol consumption is predicted to increase accidents by 0.6 percent. As expected, higher income is associated with a decrease in the number of accidents. However, the number of vehicles did not significantly influence accidents in Poland (the same result was obtained and published by the European Commission in the Road Safety Country Profile: PL). Most likely, an increase in the number of vehicles in Poland was matched by an increase in sales of much better and more reliable cars and improvements in road conditions in recent years. Finally, our results confirm that lowering the BAC level from .05 to .02 significantly reduced traffic accidents by about $7 \%$ (elasticities are calculated as in Norström [50] and Halvorsen and Palmquist [51]). It is important to note that during the time that Poland reduced its BAC level, other policies were also implemented that may be reflected in our estimates. For example, the mandatory seat belt laws (for the recent analysis of the effect of seat belt laws on lives saved, see, e.g., Houston and Richardson [52]) as well as the legislation [13] was passed during this time. Since they were introduced at a similar time, it is impossible to differentiate their effects by using regression analysis.

\section{Estimates of Suicide Rates and Vandal Behaviors}

Under the influence of alcohol, some people are more prone to violence than when they are sober. There is a number of mechanisms in which drinking may affect violent behaviors. Alcohol acts as an anesthetic, as an excuse [53], and may narrow some people's repertoire of responses to tense situations and perceptions of consequences of their actions. In this section, we examine the relationship between 
TABLE 6: BAC levels across the world.

\begin{tabular}{ll}
\hline BAC level & Countries \\
\hline zero & Croatia, Czech Republic, Hungary, Japan, Romania, Saudi Arabia, and Slovakia, \\
$0.02 \%$ & Estonia, Norway, Poland, Russia, and Sweden \\
$0.025 \%$ & Spain \\
$0.04 \%$ & Lithuania \\
$0.05 \%$ & Argentina, Australia, Austria, Belgium, Bulgaria, Denmark, Finland, France, Germany, Greece, Iceland, Israel, \\
$0.08 \%$ & Italy, Luxembourg, the Netherlands, Portugal, Serbia, Slovenia, Switzerland, and Turkey \\
\hline
\end{tabular}

Table 7: Total accidents per capita.

\begin{tabular}{lccc}
\hline & Coeff. & Std.Err. & $P$ value \\
\hline Constant & 0.029 & 0.025 & .256 \\
$\Delta$ Consumption & 0.0596 & 0.0288 & .045 \\
$\Delta$ Income & -0.0005 & 0.0003 & .120 \\
$\Delta$ Vehicles & 1.979 & 3.526 & .578 \\
BAC $_{20}$ & -0.0714 & 0.0431 & .105 \\
$R$-squared & 0.17 & & \\
\hline
\end{tabular}

TABle 8: Suicide rates per 100,000 population age 15 and older $(n=50)$.

\begin{tabular}{lccc}
\hline Variables & Coeff. & Std.Err. & $P$ value \\
\hline Constant & 5.137 & & \\
Consumption & 0.833 & 0.263 & .0027 \\
Trend & 0.146 & 0.026 & .0000 \\
$R$-squared & 0.607 & & \\
\hline
\end{tabular}

alcohol consumption and the propensity to commit suicide or vandal acts.

Figure 8 shows how the suicide rate changed in Poland from 1954 to 2005. Data on the suicide rates were taken from the Statistical Yearbook of the Republic of Poland. Since there is no other data available, we define suicide rates as the number of suicides attempted and committed per 100,000 population age of 15 and older.

In 1997, the suicide rate was highest at 20.16, and it declined steadily to 17.6 in 2005 . The suicide rate is higher in Poland than in the U.S. The World Health Organization reports that in 2004, the suicide rate in Poland was 27.9 and 4.6 per 100,000 population for males and females, respectively. For the U.S. in 2002, the corresponding numbers were 17.9 and 4.2 (see http://www.who.int/mental_health/ prevention/suicide_rates/en/index.html, accessed on October 15, 2007).

Table 8 reports estimates of the suicide rates per 100,000 population age of 15 and older in Poland. We find that per capita alcohol consumption is strongly and significantly positively related to the suicide rate. Therefore, our estimates suggest that the propensity to commit suicide is heavily influenced by drinking. An increase in consumption by 1 liter of pure alcohol per capita (age 15+) would increase the suicide rate by 0.83 . Since the coefficient on the time trend is positive and significant, the compound average annual rate

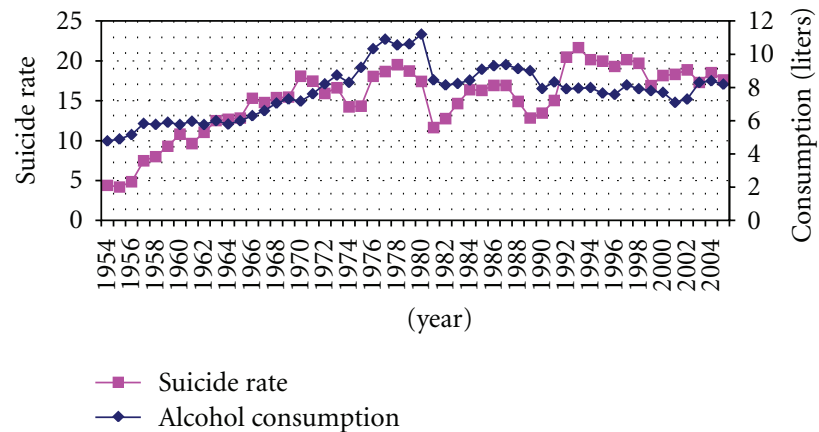

Figure 8: Suicide rate per 100,000 population age of 15 and older; 1954-2005.

TABLE 9: Violent behaviors $(n=36)$.

\begin{tabular}{lccc}
\hline Variables & Coeff. & Std.Err. & $P$ value \\
\hline Constant & 7.936 & & \\
Consumption & 1.020 & 0.261 & .0004 \\
Trend & -0.393 & 0.047 & .0000 \\
$R$-squared & 0.770 & & \\
\hline
\end{tabular}

of increase in the suicide rate, holding all other variables constant, is 15.7. As Cook and Moore [25] report, "The blood of suicide victims often contains a high percentage of alcohol [54], and receiving treatment for alcoholism or alcohol abuse is a significant risk factor for suicide [55]. Skog and Elekes [56] examined the relationship between alcohol consumption and suicides in Hungary, and found the two to be highly positively correlated." Carpenter [57] finds statistically significant reductions on the order of 7 to 10 percent in suicide among young males aged $15-17$ and $18-$ 20 associated with adoption of zero tolerance laws, no effects for slightly older males, and no consistent effects for females. Markowitz et al. [58] find that higher beer taxes and tougher drunk driving laws are negatively associated with the suicide rates by young males at ages of $15-24$.

Figure 9 shows the change in the rate of vandalism incidents per 100,000 population(age 15+) in Poland for years 1953-1988. Data on vandalism incidents were taken from the Statistical Yearbook of the Republic of Poland. The rate steadily decreased from its highest level of 12.9 per 100,000 people in 1955 to 2.4 in 1998. As with the suicide rate, vandalism may be related to heavy alcohol drinking, so it is possible that policies designed to reduce 
TABLE 10

\begin{tabular}{|c|c|c|c|c|c|c|}
\hline Variable & Definition & Mean & Std.Dev. & Min & $\operatorname{Max}$ & Number \\
\hline $\begin{array}{l}\text { Alcohol } \\
\text { consumption }\end{array}$ & Total per capita (age 15+) ethanol consumption in liters & 7.50 & 1.74 & 4.18 & 11.19 & 56 \\
\hline Beer consumption & Per capita $(15+)$ beer consumption & 1.83 & 0.74 & 0.79 & 3.89 & 56 \\
\hline $\begin{array}{l}\text { Spirits } \\
\text { consumption }\end{array}$ & Per capita $(15+)$ spirits consumption & 4.52 & 1.46 & 2.09 & 7.92 & 56 \\
\hline Wine consumption & Per capita $(15+)$ wine consumption & 1.15 & 0.47 & 0.16 & 2.16 & 56 \\
\hline Real alcohol price & CPI alcohol/total CPI & 1.04 & 0.20 & 0.75 & 1.59 & 51 \\
\hline Beer price & CPI beer/CPI & 0.22 & 0.13 & 0.10 & 0.88 & 53 \\
\hline Spirits price & CPI spirits/CPI & 2.59 & 1.67 & 1.26 & 9.22 & 53 \\
\hline Wine price & CPI wine/CPI & 1.45 & 0.86 & 0.73 & 6.99 & 53 \\
\hline Real income & Per capita real yearly income in zloty $1990=100 \%$ & 766.45 & 285.56 & 315.70 & 1371.81 & 51 \\
\hline Accidents & $\begin{array}{l}\text { Motor vehicle traffic accidents per } 100,000 \text { population } \\
\text { age } 15 \text { and older }\end{array}$ & 27.16 & 8.20 & 12.29 & 41.29 & 50 \\
\hline Liver cirrhosis & $\begin{array}{l}\text { Deaths due to liver cirrhosis per } 100,000 \text { population } \\
\text { age of } 20 \text { and older }\end{array}$ & 14.16 & 3.29 & 4.98 & 18.35 & 47 \\
\hline Suicide rate & $\begin{array}{l}\text { Attempted and committed suicides per } 100,000 \\
\text { population age of } 15 \text { and older }\end{array}$ & 15.13 & 4.25 & 4.19 & 21.66 & 52 \\
\hline Vandal & Number of vandal accidents per 100,000 population & 7.20 & 3.01 & 2.40 & 15.10 & 36 \\
\hline Population $65+$ & $\%$ Population age of 65 and older & 9.59 & 2.11 & 5.30 & 13.30 & 48 \\
\hline Population 15-20 & $\%$ Population between 15 and 20 & 8.40 & 1.25 & 6.50 & 10.70 & 48 \\
\hline $\begin{array}{l}\text { Free market } \\
\text { variable }\end{array}$ & Dummy variable $=1$ on and after 1989 & 0.30 & 0.46 & 0.00 & 1.00 & 56 \\
\hline Vehicles & Number of vehicles per capita $(15+)$ & 4143.04 & 4526.07 & 72.60 & 14644.00 & 56 \\
\hline BAC01 & A dummy variable $=1$ for BAC 0.01 & 0.43 & 0.50 & 0.00 & 1.00 & 56 \\
\hline Population & Total population in thousands & 34117.80 & 4188.68 & 25035.00 & 38660.00 & 56 \\
\hline
\end{tabular}

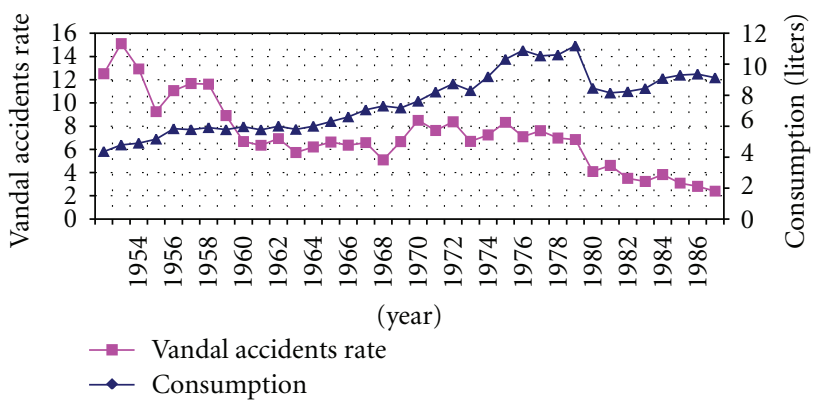

Figure 9: Vandalism per 100,000 population in Poland for years 1953-1988.

alcohol use by increasing taxes will also reduce violence. In the U.S., for example, Markowitz and Grossman [59] find that higher alcohol prices are negatively related to spousal abuse; Scribner et al. [60] find that higher density of retail outlets licensed to sell alcohol is positively related to violent crime; Jones et al. [61] find that higher minimum legal drinking ages are negatively related to various forms of violent death among youth homicide; Sen [62] reports an inverse relationship between beer taxes and child homicide deaths (with the elasticity approximately -0.19) and a direct relationship between alcohol retail outlet density and child homicide deaths (the elasticity approximately 0.16 ).
We report our regression results in Table 9. The estimated magnitudes suggest substantial effects of alcohol consumption on vandalism rates. An increase in consumption by 1 liter of pure alcohol per capita (age 15+) would increase the rate of vandalism incidents by 1 . Since the coefficient on the time trend is positive and significant, the compound average annual rate of decrease in vandalism rate, holding all other variables constant, is -32.5 .

\section{Conclusions and Policy Implications}

We presented a comprehensive study on the subject of alcohol demand and adverse effects of drinking in Poland. First, we tested the rational addiction model of alcohol demand. Next, we estimated a system of demand equations for beer, spirits, and wine that allowed us to find substitution effects between drinks. Finally, we investigated the effects of alcohol consumption on traffic accidents, suicide rates, and violent behaviors.

We found support for the myopic model of alcohol demand in Poland. The final impact of any price changes on alcohol revenue depends on the substitutability among alcoholic drinks. The regression of the AIDS demand system suggests that spirits and beer are complements, spirits and wine are substitutes, and beer and wine are price independent. Also, beer consumption is income inelastic, spirits consumption is elastic, and wine consumption is somewhat 
income elastic. All demands for alcoholic beverages are price inelastic, however, to a different degree. To maximize an increase in the alcohol revenue, the largest tax hike should be for beer and the smallest for spirits. On the other hand, if the government policy was to reduce alcohol consumption (because of the negative externalities it produces), then this tax hike would be largely ineffective. A uniform increase in beer, spirits, and wine taxes will result in the greatest reduction in spirits consumption and the smallest in beer consumption. Additionally, our results showed that traffic accidents, the suicide rate, and the violent behaviors rate would all decrease with decrease in alcohol consumption making a policy of higher alcohol taxes, if effective, very desirable. However, since our results show that alcohol demand is price inelastic (especially for binge drinkers), any tax policy may be less effective than expected. Therefore, other policies should be implemented together with tax increases. The combined effect of the change from socialism to the market economy and government policies such as lowering the BAC level and introduction of seat belt laws significantly reduced traffic accidents in Poland. Poland's reduction in BAC level from $0.05 \%$ to $0.02 \%$ in 1982 was shown to significantly reduce road fatalities independently of the increase in Poland's standard of living or the number of vehicles on roads. Since BAC level of $0.02 \%$ is still one of the lowest in Europe and the U.S., this may be an example for other countries to follow. Our results are limited to other cultural changes taken place in Poland in the 80s and cultural attitudes toward drinking in Poland. Similar analysis using methodologies presented in our paper could be conducted in other countries interested in reducing the problems associated with heavy alcohol drinking.

\section{Appendices}

\section{A.}

See Table 10.

B.

(a) The ordinary (uncompensated) conditional price elasticities of demand are

$$
\begin{aligned}
h_{i j} & =\frac{\partial q_{i}}{\partial p_{i}} \frac{p_{i}}{q_{i}}=\left[-\frac{M}{p_{i}^{2}} w_{i}+\frac{M}{p_{i}}\left(-\beta_{i} w_{i} \frac{1}{p_{i}}+\pi_{i i} \frac{1}{p_{i}}\right)\right] \frac{p_{i}}{q_{i}} \\
& =-w_{i} \frac{M}{p_{i} q_{i}}-\frac{M}{p_{i} q_{i}} \beta_{i} w_{i}+\frac{M}{p_{i} q_{i}} \pi_{i j}=-1-\beta_{i}+\frac{\pi_{i j}}{w_{i}}
\end{aligned}
$$

for $i=j$;

$$
\begin{aligned}
h_{i j} & =\frac{\partial q_{i}}{\partial p_{j}} \frac{p_{j}}{q_{i}}=\frac{p_{j}}{q_{i}} \frac{M}{p_{i}}\left(-\beta_{i} w_{j} \frac{1}{p_{j}}+\pi_{i j} \frac{1}{p_{j}}\right) \\
& =-\frac{M}{p_{i} q_{i}} \beta_{i} w_{j}+\frac{M}{p_{i} q_{i}} \pi_{i j}=\frac{\pi_{i j}-\beta_{i} w_{j}}{w_{i}}
\end{aligned}
$$

for $i \neq j$; (b) The conditional compensated price elasticities of demand are calculated using Slutsky equation

$$
\begin{aligned}
\epsilon_{i j} & =-1-\beta_{i}+\frac{\pi_{i j}}{w_{i}}+w_{i}\left(1+\frac{\beta_{i}}{w_{i}}\right) \\
& =-1-\beta_{i}+\frac{\pi_{i j}}{w_{i}}+w_{i}+\beta_{i} \\
& =-1+w_{i}+\frac{\pi_{i j}}{w_{i}}
\end{aligned}
$$

for $i=j$,

$$
\epsilon_{i j}=\frac{\pi_{i j}-\beta_{i} w_{j}}{w_{i}}+w_{j}\left(1+\frac{\beta_{i}}{w_{i}}\right)=w_{j}+\frac{\pi_{i j}}{w_{i}}
$$

for $i \neq j$.

(c) The conditional income elasticity of demand is

$$
\begin{aligned}
\epsilon_{\mathrm{im}} & =\frac{\partial q_{i}}{\partial M} \frac{M}{q_{i}}=\frac{M}{q_{i}}\left[\frac{1}{p_{i}} w_{i}+\frac{M}{p_{i}}\left(\beta_{i} \frac{1}{M}\right)\right] \\
& =w_{i} \frac{M}{p_{i} q_{i}}+\beta \frac{M}{p_{i} q_{i}} \\
& =1+\frac{\beta_{i}}{w_{i}}
\end{aligned}
$$

(d) The ordinary unconditional price elasticities of demand are

$$
\begin{aligned}
\frac{\partial q_{i}}{\partial p_{i}} \frac{p_{i}}{q_{i}}= & \frac{p_{i}}{q_{i}}\left[\frac{Y \varphi_{1} w_{i}\left(1 / p_{i}\right) p_{i}-M}{p_{i}^{2}} w_{i}\right. \\
& \left.\quad+\frac{M}{p_{i}}\left(\beta_{i} \frac{1}{M} Y \varphi_{1} w_{i} \frac{1}{p_{i}}-\beta_{i} w_{i} \frac{1}{p_{i}}+\pi_{i i} \frac{1}{p_{i}}\right)\right] \\
= & \frac{Y}{M} \varphi_{1} w_{i}-1+\beta_{i} \frac{Y}{M} \varphi_{1}-\beta_{i}+\frac{\pi_{i i}}{w_{i}}
\end{aligned}
$$

for $i=j$,

$$
\begin{aligned}
\frac{\partial q_{i}}{\partial p_{j}} \frac{p_{j}}{q_{i}}= & \frac{p_{i}}{p_{i} q_{i}}\left[\frac{M}{M} Y \varphi_{1} w_{j} \frac{1}{p_{j}} w_{i}\right. \\
& \left.+M\left(\beta_{i} \frac{1}{M} Y \varphi_{1} w_{j} \frac{1}{p_{j}}-\beta_{i} w_{j} \frac{1}{p_{j}}+\pi_{i j} \frac{1}{p_{j}}\right)\right] \\
= & \frac{Y}{M} \varphi_{1} w_{j}+\frac{w_{j}}{w_{i}} \beta_{i} \varphi_{1} \frac{Y}{M}-\frac{w_{j}}{w_{i}} \beta_{i}+\frac{\pi_{i j}}{w_{i}}=w_{i} \frac{p_{i}}{p_{i} q_{i}} \\
= & \frac{Y}{M} \varphi_{1} w_{j}\left(1+\frac{\beta_{i}}{w_{i}}\right)+\frac{\pi_{i j}-\beta_{i} w_{j}}{w_{i}}
\end{aligned}
$$

for $i \neq j$. 
(f) The unconditional income elasticity of demand is

$$
\begin{aligned}
\frac{\partial q_{i}}{\partial Y} \frac{Y}{q_{i}} & =\frac{Y}{p_{i} q_{i}}\left[\left(\frac{M}{Y}+\frac{M}{M} \varphi_{2}\right) w_{i}+M\left(\beta_{i} \frac{1}{M} \frac{M}{Y}+\beta_{i} \frac{1}{M} \varphi_{2}\right)\right] \\
& =\frac{M}{p_{i} q_{i}} Y\left(\frac{w_{i}}{Y}+\frac{w_{i} \varphi_{2}}{M}+\frac{\beta_{i}}{Y}+\frac{\beta_{i} \varphi_{2}}{M}\right) \\
& =1+\frac{\beta_{i}}{w_{i}}+\frac{Y \varphi_{2}}{M}+\frac{Y \varphi_{2} \beta_{i}}{M w_{i}} .
\end{aligned}
$$

\section{JEL Classifications}

Il (Health), H2 (Taxation), F0 (International), and C3 (Econometrics).

\section{Acknowledgment}

This research was supported by the grant from the National Academy of Sciences.

\section{References}

[1] World Health Organization (WHO), "The European health report," 2002, http://www.euro.who.int/document/e76907.pdf.

[2] H. Harwood, D. Fountain, and G. Livermore, "The Economic Costs ofAlcohol \& Drug Abuse in the U.S," National Instituteon Drug Abuse and National Institute on Alcohol Abuse and Alcoholism, Rockville, Md, USA, 1992, http://www.nida.nih .gov/economiccosts/index.html.

[3] World Health Organization (WHO), The World Health Report, WHO, Geneva, Switzerland, 2003.

[4] D. Albalate, "Lowering blood alcohol content levels to save lives: the European experience," Journal of Policy Analysis and Management, vol. 27, no. 1, pp. 20-39, 2008.

[5] W. J. Florkowski and K. T. McNamara, "Policy implications of alcohol and tobacco demand in Poland," Journal of Policy Modeling, vol. 14, no. 1, pp. 93-98, 1992.

[6] D. J. Young and A. Bielińska-Kwapisz, "Alcohol taxes and beverage prices," National Tax Journal, vol. 55, no. 1, pp. 5773, 2002.

[7] J. P. Nelson and J. R. Moran, "Advertising and US alcoholic beverage demand: system-wide estimates," Applied Economics, vol. 27, no. 12, pp. 1225-1236, 1995.

[8] J. P. Nelson, "Economic and demographic factors in U.S. alcohol demand: a growth-accounting analysis," Empirical Economics, vol. 22, no. 1, pp. 83-102, 1997.

[9] D. J. Young and A. Bielińska-Kwapisz, "Alcohol consumption, beverage prices and measurement error," Journal of Studies on Alcohol, vol. 64, no. 2, pp. 235-238, 2003.

[10] D. J. Young and A. Bielińska-Kwapisz, "Alcohol prices, consumption, and traffic fatalities," Southern Economic Journal, vol. 72, no. 3, pp. 690-703, 2006.

[11] J. Moskalewicz, "Lessons to be learnt from Poland's attempt at moderating its consumption of alcohol," Addiction, vol. 88, pp. 135S-142S, 1993.

[12] A. Bielewicz and J. Moskalewicz, "Temporary prohibition: the Gdansk experience, August 1980," Contemporary Drug Problems, vol. 11, no. 3, pp. 367-381, 1982.
[13] "The Upbringing in Sobriety and Counteracting Alcoholism Act (Ustawa o Wychowaniu w Trzezwosci i PrzeciwdzialaniuAlcoholismowi)," DziennikUstaw, 35, 1982.

[14] World Health Organization (WHO), Global Status Report on Alcohol 2004, Department of Mental Health and Substance Abuse, WHO, Geneva, Switzerland, 2004.

[15] S. Popova, J. Rehm, J. Patra, and W. Zatonski, "Comparing alcohol consumption in central and eastern Europe to other European countries," Alcohol and Alcoholism, vol. 42, no. 5, pp. 465-473, 2007.

[16] Central Statistical Office, Ed., Statistical Yearbooks of the Republic of Poland, 1956-2006, Central Statistical Office, Warsaw, Poland.

[17] Central Statistical Office, Ed., Demographic Yearbooks of Poland 1950-2005, Central Statistical Office, Warsaw, Poland.

[18] G. S. Becker and K. M. Murphy, "A theory of rational addiction," Journal of Political Economy, vol. 96, no. 4, pp. 675700, 1988.

[19] T. M. Waters and F. A. Sloan, "Why do people drink? Test of the rational addiction model," Applied Economics, vol. 27, pp. 727-736, 1995.

[20] M. Grossman, F. J. Chaloupka, and I. Sirtalan, "An empirical analysis of alcohol addiction: results from the monitoring the future panels," Economic Inquiry, vol. 36, no. 1, pp. 39-48, 1998.

[21] S. F. Leung and C. E. Phelps, "My kingdom for a drink ... ? A review of estimates of the price sensitivity of demand for alcoholic beverages," in Economics and the Prevention of Alcohol-Related Problems: Proceedings of a Workshop on Economic and Socioeconomic Issues in the Prevention of AlcoholRelated Problems October 1991, M. E. Hilton and G. Bloss, Eds., vol. 1993 of NIAAA Research Monograph no. 25 1-31, Bethesda, Md, USA, October 1991.

[22] P. J. Cook, "The effect of liquor taxes on drinking, cirrhosis, and auto accidents," in Alcohol and Public Policy, M. H. Moore and D. R. Gerstein, Eds., pp. 255-285, National Academy Press, Washington, DC, USA, 1981.

[23] P. J. Cook and G. Tauchen, "The effect of liquor taxes on heavy drinking," Bell Journal of Economics, pp. 379-390, 1982.

[24] R. W. Brown and R. T. Jewell, "County-level alcohol availability and cirrhosis mortality," Eastern Economic Journal, vol. 22, pp. 291-301, 1996.

[25] P. J. Cook and M. J. Moore, "Alcohol," in Prepared for the Handbook of Health Economics, J. P. Newhouse and A. Culyer, Eds., 2000.

[26] K. Bruun, G. Edwards, M. Lumio et al., "Alcohol control policies," in Public Health Perspective, Aurasen Kirjapaino, Forssa, Finland, 1975.

[27] K. Lelbach, "Organic pathology related to volume and pattern of alcohol use," in Research Advances in Alcohol and Drug Problems, R. J. Gibbins et al., Ed., vol. 1, John Wiley \& Sons, New York, NY, USA, 1974.

[28] J. A. Johnson and E. H. Oksanen, "Socio-economic determinants of the consumption of alcoholic beverages," Applied Economics, vol. 6, pp. 124-135, 1974.

[29] J. A. Johnson and E. H. Oksanen, "Estimation of demand for alcoholic beverages in Canada from pooled time series and cross sections," The Review of Economics and Statistics, vol. 59, pp. 113-118, 1977.

[30] H.-H. Lau, "Cost of alcoholic beverages as a determinant of alcohol consumption," in Research Advances in Alcohol and Drug Problems, A Wiley-Biomedical Health Publication, chapter 6, John Wiley \& Sons, New York, NY, USA, 1975. 
[31] D. Coate and M. Grossman, "Effects of alcoholic beverage prices and legal drinking ages on youth alcohol use," Journal of Law and Economics, vol. 31, no. 1, pp. 145-171, 1988.

[32] A. S. Deaton and J. Muellbauer, "An almost ideal demand system," The American Economic Review, vol. 70, no. 3, pp. 312-326, 1980.

[33] K. W. Clements and L. W. Johnson, "The demand for beer, wine, and spirits: a system-wide analysis," Journal of Business, vol. 56, pp. 273-304, 1983.

[34] K. W. Clements and S. Selvanathan, "The economic determinants of alcohol consumption," Australian Journal of Agricultural Economics, vol. 35, no. 2, pp. 209-231, 1991.

[35] K. W. Clements and E. A. Selvanathan, "Alcohol consumption," in Theil and Clements, Applied Demand Analysis: Results from System-Wide Approaches, pp. 185-264, Ballinger Publishing, Cambridge, Mass, USA, 1987.

[36] M. H. Duffy, "Advertising and the inter-product distribution of demand. A Rotterdam model approach," European Economic Review, vol. 31, no. 5, pp. 1051-1070, 1987.

[37] D. Heien and G. Pompelli, "The demand for alcoholic beverages: economic and demographic effects," Southern Economic Journal, vol. 55, no. 3, pp. 759-770, 1989.

[38] A. A. Andrikopoulos, J. A. Brox, and E. Carvalho, "The demand for domestic and imported alcoholic beverages in Ontario, Canada: a dynamic simultaneous equation approach," Applied Economics, vol. 29, no. 7, pp. 945-953, 1997.

[39] F. J. Chaloupka, H. Saffer, and M. Grossman, "Alcohol control policies and motor-vehicle fatalities," Journal of Legal Studies, vol. 22, no. 1, pp. 161-86, 1993.

[40] F. A. Sloan, B. A. Reilly, and C. M. Schenzler, "Tort liability versus other approaches for deterring careless driving," International Review of Law and Economics, vol. 14, no. 1, pp. 5371, 1994.

[41] C. J. Ruhm, "Economic conditions and alcohol problems," Journal of Health Economics, vol. 14, no. 5, pp. 583-603, 1995.

[42] C. J. Ruhm, "Alcohol policies and highway vehicle fatalities," Journal of Health Economics, vol. 15, no. 4, pp. 435-454, 1996.

[43] B. L. Benson, D. W. Rasmussen, and B. D. Mast, "Deterring drunk driving fatalities: an economics of crime perspective," International Review of Law and Economics, vol. 19, no. 2, pp. 205-255, 1999.

[44] T. S. Dee, "State alcohol policies, teen drinking and traffic fatalities," Journal of Public Economics, vol. 72, no. 2, pp. 289315, 1999.

[45] T. S. Dee, "The complementarity of teen smoking and drinking," Journal of Health Economics, vol. 18, no. 6, pp. 769793, 1999.

[46] B. D. Mast, B. L. Benson, and D. W. Rasmussen, "Beer taxation and alcohol-related traffic fatalities," Southern Economic Journal, vol. 66, no. 2, pp. 214-249, 1999.

[47] D. J. Young and T. W. Likens, "Alcohol regulation and auto fatalities," International Review of Law and Economics, vol. 20, no. 1, pp. 107-126, 2000.

[48] D. Eisenberg, "Evaluating the effectiveness of policies related to drunk driving," Journal of Policy Analysis and Management, vol. 22, no. 2, pp. 249-274, 2003.

[49] T. S. Dee, "Does setting limits save lives? The case of 0.08 BAC laws," Journal of Policy Analysis and Management, vol. 20, no. 1, pp. 111-128, 2001.

[50] T. Norström, "Alcohol and suicide in Scandinavia," British Journal of Addiction, vol. 83, no. 5, pp. 553-559, 1988.
[51] R. Halvorsen and R. Palmquist, "The interpretation of dummy variables in semilogarithmic equations," American Economic Review, vol. 70, pp. 474-475, 1980.

[52] D. J. Houston and L. E. Richardson, "Reducing traffic fatalities in the American States by upgrading seat belt use laws to primary enforcement," Journal of Policy Analysis and Management, vol. 25, no. 3, pp. 645-659, 2006.

[53] P. J. Cook and M. J. Moore, "Economic perspectives on alcohol-related violence," in Alcohol-Related Violence: Interdisciplinary Perspectives and Research Directions, S. E. Martin, Ed., NIH Publication No. 93-3496, pp. 193-212, National Institute on Alcohol Abuse and Alcoholism, Rockville, Md, USA, 1993.

[54] L. Hayward, S. R. Zubrick, and S. Silburn, "Blood alcohol levels in suicide cases," Journal of Epidemiology and Community Health, vol. 46, no. 3, pp. 256-260, 1992.

[55] B. Draper, "Suicidal behaviour in the elderly," International Journal of Geriatric Psychiatry, vol. 9, no. 8, pp. 655-661, 1994.

[56] O.-J. Skog and Z. Elekes, "Alcohol and the 1950-1990 Hungarian suicide trend-is there a causal connection?" Acta Sociologica, vol. 36, pp. 33-46, 1993.

[57] C. Carpenter, "Heavy alcohol use and youth suicide: evidence from tougher drunk driving lows," Journal of Policy Analysis and Management, vol. 23, no. 4, pp. 831-842, 2004.

[58] S. Markowitz, P. Chatterji, and R. Kaestner, "Estimating the impact of alcohol policies on youth suicides," Journal of Mental Health Policy and Economics, vol. 6, no. 1, pp. 37-46, 2003.

[59] S. Markowitz and M. Grossman, "The effects of beer taxes on physical child abuse," Journal of Health Economics, vol. 19, no. 2, pp. 271-282, 2000.

[60] R. A. Scribner, D. P. MacKinnon, and J. H. Dwyer, "The risk of assaultive violence and alcohol availability in Los Angeles County," American Journal of Public Health, vol. 85, no. 3, pp. 335-340, 1995.

[61] N. E. Jones, C. F. Pieper, and L. S. Robertson, "The effect of legal drinking age on fatal injuries of adolescents and young adults," American Journal of Public Health, vol. 82, no. 1, pp. 112-115, 1992.

[62] B. Sen, "The relationship between Beer taxes, other alcohol policies, and child homicide deaths," Topics in Economic Analysis \& Policy, vol. 6, no. 1, article 15, 2006. 


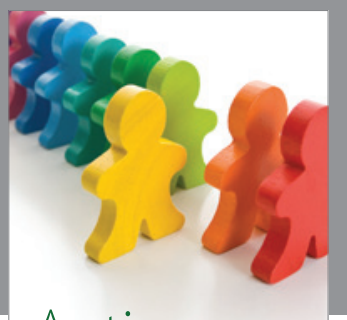

Autism

Research and Treatment
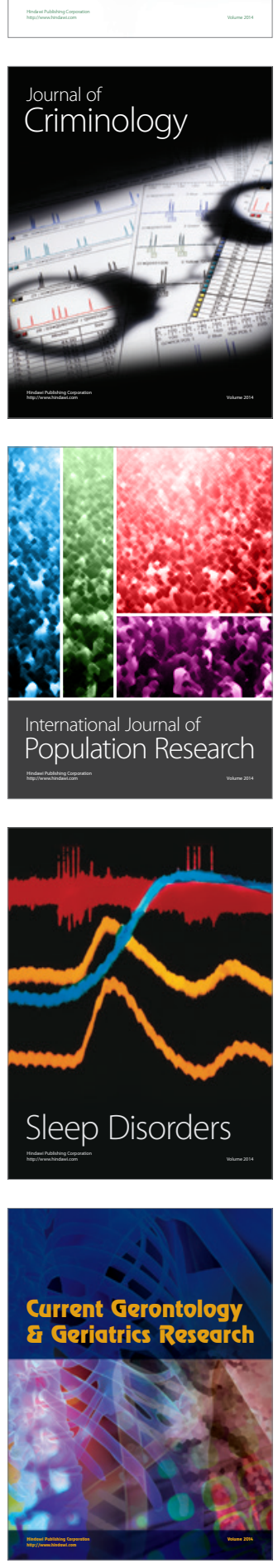
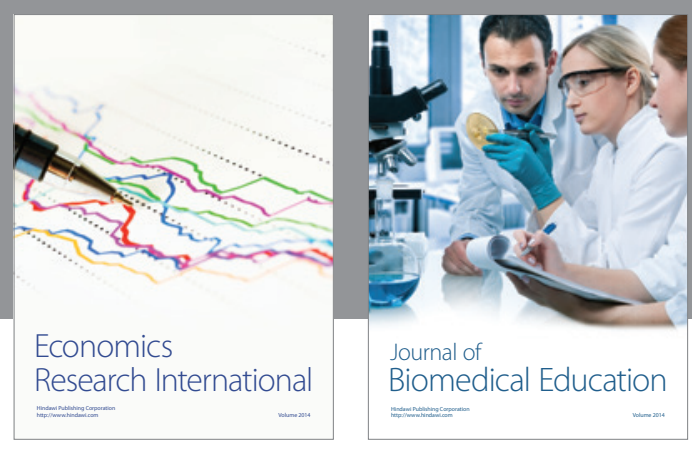

Journal of

Biomedical Education

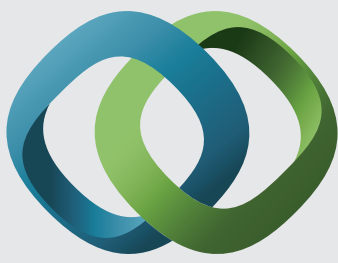

\section{Hindawi}

Submit your manuscripts at

http://www.hindawi.com
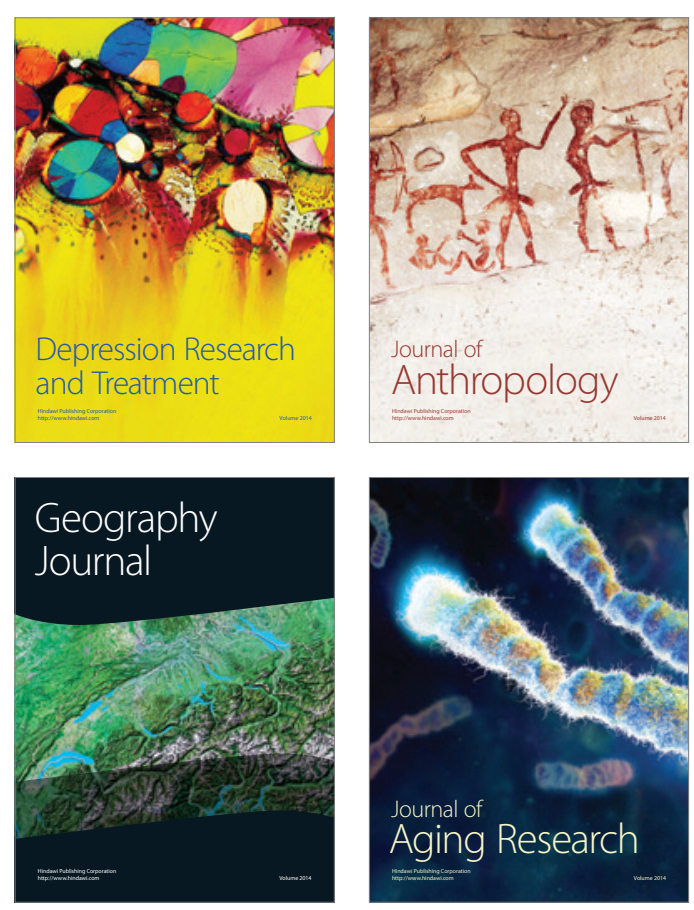

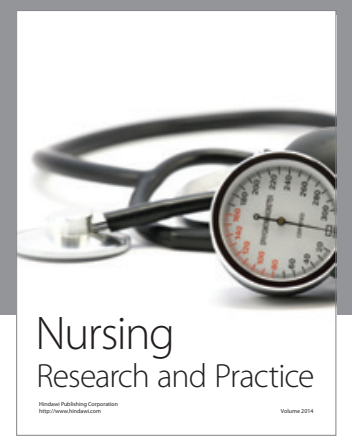

Nursing

Research and Practice

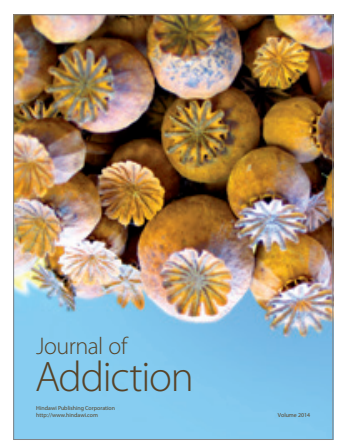

Child Development

Research

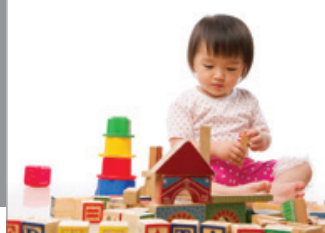

迥
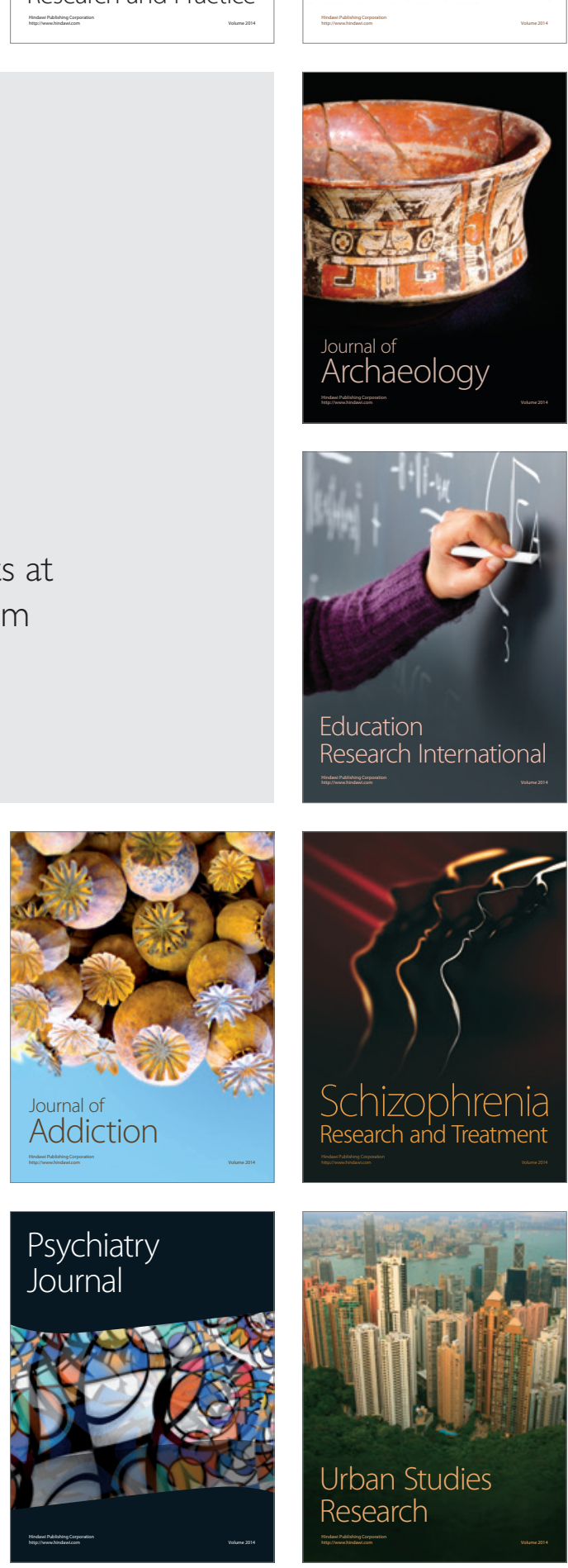